\title{
Electrochemical Systems for Renewable Energy Conversion from Salinity and Proton Gradients
}

\author{
William G. Morais, Gilberto Lima, Wellington J. A. S. Gomes and Fritz Huguenin* \\ Departamento de Química, Faculdade de Filosofia, Ciências e Letras de Ribeirão Preto, \\ Universidade de São Paulo, 14040-910 Ribeirão Preto-SP, Brazil
}

\begin{abstract}
Ever-rising energy demand, fossil fuel dependence, and climate issues have harmful consequences to the society. Exploring clean and renewable energy to diversify the world energy matrix has become an urgent matter. Less explored or unexplored renewable energy sources like the salinity and proton gradient energy are an attractive alternative with great energy potential. This paper discusses important electrochemical systems for energy conversion from natural and artificial concentration gradients, namely capacitive mixing (CapMix), mixing entropy batteries (MEB), and neutralization batteries (NB); the working principle and thermodynamic formalism of these systems; and the materials employed in the assembly of these systems.
\end{abstract}

Keywords: electrochemical energy conversion and storage, renewable energy, salinity gradient energy, mixing entropy batteries, neutralization batteries

\section{Introduction}

Increased energy demand associated with the production chain, the popularity of electronic devices, the massive use of fossil fuel combustion vehicles, the consumer society, and population growth has led the world to face a transition point in terms of energy consumption. ${ }^{1}$ For instance, the evergrowing demand for electricity, which is the most common form of energy consumption worldwide, surpasses the energy production rate. Another issue is that coal remains the main electricity source although its combustion releases $1.0 \mathrm{~kg}$ of $\mathrm{CO}_{2}$ per $\mathrm{kWh}$ of produced electric energy. ${ }^{2,3}$

Environmental impacts due to energy consumption and production have been discussed along the years, especially the impacts related to climate change. Substituting nonrenewable sources or mitigating their presence in the world energy matrix can help to prevent irreversible climate changes as well as the collapse of civilization. The current participation of renewable sources in the world energy matrix stands around $19.2 \%{ }^{4}$ The scientific community considers that improving this percentage is an urgent matter.

Solar, wind, and hydropower are the renewable energy sources that have attracted scientists' attention the most successfully throughout the years, followed by geothermal

*e-mail: fritz@ @ffclrp.usp.br

This paper is part of the PubliSBQ Special Issue "IUPAC-2017" (http://publi.sbq.org.br/). energy and biomass. ${ }^{5-7}$ Investigation into less explored or unexplored renewable sources can help to diversify the world energy matrix in the mid- and in the long-term. ${ }^{8}$ Salinity gradient energy (SGE) or blue energy is among unexplored clean and renewable energy sources with great potential for energy storage. This technology only depends on the difference between the salinity of two water reservoirs such as seawater and river water. ${ }^{9-11}$ Similarly, salinity and/or acidic concentration gradients generated by human actions, e.g., industries and sewage treatment stations, could be used to harvest uncollected energy, thereby contributing to more sustainable growth. ${ }^{12}$

\section{Salinity Gradient Energy}

SGE, which becomes available when two solutions of different concentrations mix, is a less known and a less explored renewable energy source. A natural example of this situation is the spontaneous mixing of river water and seawater in deltas and estuaries. ${ }^{12}$ The energy associated with this mixing process is not normally harvested in nature. ${ }^{13}$ The global hydrological cycle ensures that SGE is sustainable: the thermal energy related to sunlight incidence partially drives the cycle, which is an open system where seawater evaporation and precipitation over the continent feed river waters. Consequently, the difference between the salinity of natural water reservoirs is preserved: the 
concentration of the most abundant solute $(\mathrm{NaCl})$ is 0.024 and $0.60 \mathrm{~mol} \mathrm{~L}^{-1}$ in river water and seawater, respectively. ${ }^{14}$ In this context, it is thermodynamically possible to obtain work in an almost inexhaustible $\mathrm{CO}_{2}$-free way by taking advantage of the free energy variation associated with entropy changes in the mixing process. ${ }^{9}$ In practical terms, SGE conversion and energy storage require an appropriate system to control the mixing of solutions with different salinities.

\section{Salinity Gradient Energy Potential}

When two solutions with different compositions mix spontaneously, the Gibbs free energy, $\Delta \mathrm{G}_{\text {mix }}$, associated with the mixture decreases. Control of this mixing process enables conversion of the entropic energy of the salinity gradient to work. $\Delta \mathrm{G}_{\text {mix }}$ represents the maximum theoretical energy that can be extracted from the salinity gradient, but the way the solutions mix is not considered. Equation 1 expresses $\Delta \mathrm{G}_{\text {mix }}$ in aqueous solutions containing strong electrolytes.

$$
\begin{aligned}
\Delta \mathrm{G}_{\text {mix }}= & \mathrm{G}_{\mathrm{m}}-\left(\mathrm{G}_{\mathrm{c}}+\mathrm{G}_{\mathrm{d}}\right)=\sum_{\mathrm{i}}^{\mathrm{t}}\left[\left(\mathrm{n}_{\mathrm{i}, \mathrm{c}}+\mathrm{n}_{\mathrm{i}, \mathrm{d}}\right) \mathrm{RT} \ln \left(\gamma_{\mathrm{i}, \mathrm{m}} \mathrm{x}_{\mathrm{i}, \mathrm{m}}\right)\right. \\
& \left.-\left(\mathrm{n}_{\mathrm{i}, \mathrm{c}} \mathrm{R} \ln \left(\gamma_{\mathrm{i}, \mathrm{c}} \mathrm{x}_{\mathrm{i}, \mathrm{c}}\right)+\mathrm{n}_{\mathrm{i}, \mathrm{d}} \mathrm{R} \ln \left(\gamma_{\mathrm{i}, \mathrm{d}} \mathrm{x}_{\mathrm{i}, \mathrm{d}}\right)\right)\right]
\end{aligned}
$$

where the subscripts $\mathrm{m}, \mathrm{c}$, and $\mathrm{d}$ correspond to the mixed, concentrated, and diluted solutions, respectively; $\mathrm{G}$ is the Gibbs free energy; $n$ is the number of moles of species $i$; $t$ is the total number of species; $\mathrm{R}$ is the ideal gas constant; $\mathrm{T}$ is the temperature; $x_{i}$ is the molar fraction of species $i$; and $\gamma_{i}$ is the activity coefficient of species $i$, which is a function of temperature, pressure, and solution composition and refers to deviation from ideality. $\Delta \mathrm{G}_{\text {mix }}$ can also be expressed as a function of the solution volumes: ${ }^{15}$

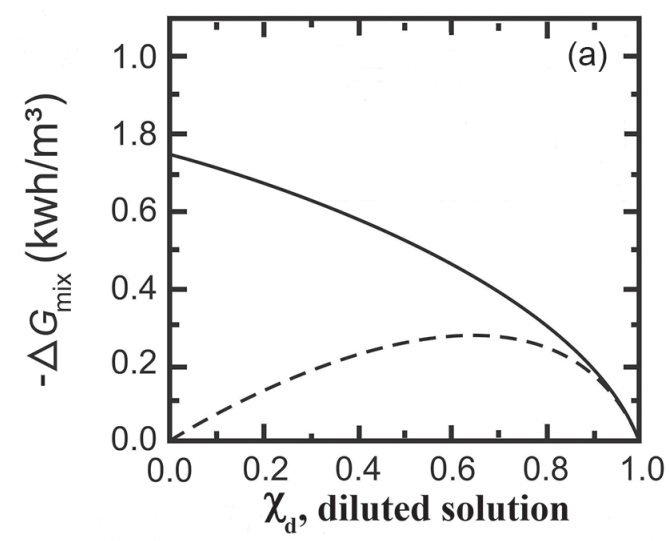

$\Delta \mathrm{G}_{\text {mix }}=\mathrm{RT} \sum_{\mathrm{i}}^{\mathrm{t}}\left[\mathrm{c}_{\mathrm{i}, \mathrm{m}} \mathrm{V}_{\mathrm{m}} \ln \left(\mathrm{x}_{\mathrm{i}, \mathrm{m}}\right)-\left(\mathrm{c}_{\mathrm{i}, \mathrm{c}} \mathrm{V}_{\mathrm{c}} \ln \left(\mathrm{x}_{\mathrm{i}, \mathrm{c}}\right)+\mathrm{c}_{\mathrm{i}, \mathrm{d}} \mathrm{V}_{\mathrm{d}} \ln \left(\mathrm{x}_{\mathrm{i}, \mathrm{d}}\right)\right)\right]$

where $\mathrm{c}$ is the molar concentration, and $\mathrm{V}$ is the volume.

Figure 1a shows $\Delta \mathrm{G}_{\text {mix }}$ per volume of the diluted solution (the limiting factor) as a function of the freshwater $(1.5 \mathrm{mM})$ and seawater $(0.6 \mathrm{M})$ volumetric fraction. In this case, the molar fraction is approximated to the ratio between the diluted solution volume and the mixture total volume. ${ }^{16}$ The maximum free energy variation per freshwater volume unit is $0.76 \mathrm{kWh} \mathrm{m}^{-3}$, when $\mathrm{x}_{\mathrm{d}} \rightarrow 0$. The larger the $x_{d}$, the smaller the harvested energy. When the energy is normalized by the mixture total volume $\left(\mathrm{V}_{\mathrm{c}}+\mathrm{V}_{\mathrm{d}}\right)$, the maximum $\Delta \mathrm{G}_{\text {mix }}$ value occurs at $\mathrm{x}_{\mathrm{d}}=0.63$, which means that $0.44 \mathrm{kWh} \mathrm{m}^{-3}$ energy can be harvested; this value represents $58 \%$ of $\Delta \mathrm{G}_{\text {mix }}$ when $\mathrm{x}_{\mathrm{d}} \rightarrow 0$.

The maximum available energy rises as the concentration gradient increases, as seen in Figure $1 \mathrm{~b}$ for systems consisting of freshwater and seawater, brine and effluent water, pre-concentrated solution and effluent water, and supersaturated solution and freshwater. Based on these data, a power plant can produce up to $100 \mathrm{MW}$ of energy for a flow of $40 \mathrm{~m}^{3} \mathrm{~s}^{-1}$ of freshwater mixed with seawater. ${ }^{17}$ However, only a fraction of this theoretical energy can be effectively extracted. Indeed, a reversible thermodynamic process must be applied to convert $\Delta \mathrm{G}_{\text {mix }}$ into maximum useful work. According to the second law of thermodynamics, energy dissipation is inevitable (in systems that do not operate in equilibrium conditions), which means that the performed work is smaller than $\Delta \mathrm{G}_{\text {mix }}$. Despite this natural restriction, knowing that the flow of freshwater that is annually discharged into the oceans ranges from $37 \times 10^{3}$ to $46 \times 10^{3} \mathrm{~km}^{3}$, SGE remains an important renewable energy source. For these conditions, around $28 \times 10^{3}-35 \times 10^{3}$ TWh could be harvested per year for $\mathrm{x}_{\mathrm{d}} \rightarrow 0$. When $\Delta \mathrm{G}_{\text {mix }}$ per mixture volume unit is

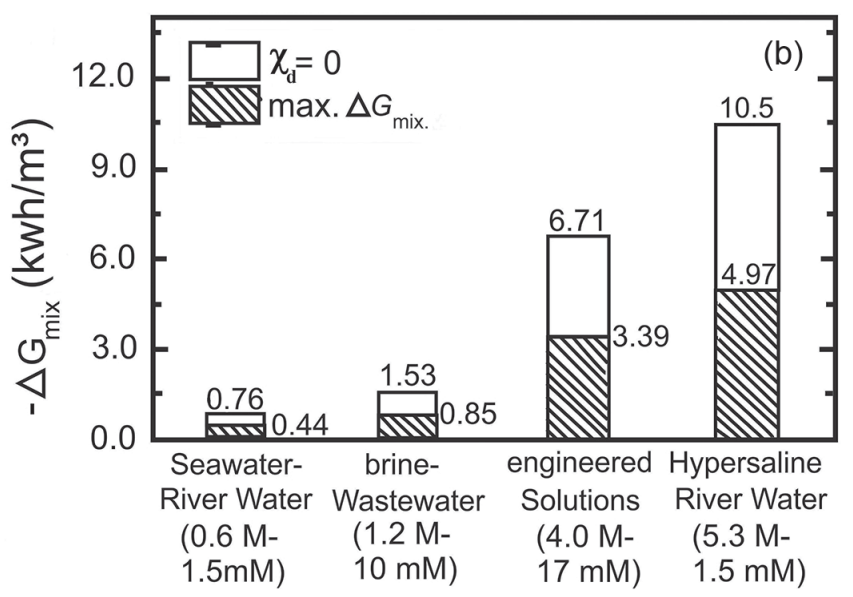

Figure 1. (a) Variation in the Gibbs free energy normalized by the diluted solution volume and by the mixture total volume as a function of the diluted solution volumetric fraction; (b) variation in the Gibbs free energy normalized by the diluted solution volume for four different systems. Adapted from Yip et al. ${ }^{18}$ 
maximized, the harvested energy could lie between $16 \times 10^{3}$ and $20 \times 10^{3} \mathrm{TWh}$ per year for $\mathrm{x}_{\mathrm{d}}=0.63$. The magnitude of this energy is close to the electric energy that is currently consumed worldwide. In 2013, for example, the world energy consumption was $19.5 \times 10^{3} \mathrm{TWh}^{18}$

\section{Salinity and Proton Gradient Energy-Based Systems}

Since the first studies proposed by Pattle in $1954,{ }^{19}$ different types of systems and technologies have been proposed to harvest renewable energy by mixing solutions of different concentrations. Pressure retarded osmosis $(\mathrm{PRO}),{ }^{20}$ reversible electrodialysis (RED), ${ }^{21}$ capacitive mixing (CapMix), ${ }^{22}$ mixing entropy batteries (MEB), ${ }^{17}$ and neutralization batteries $(\mathrm{NB})^{23}$ are some of the relevant studied systems. The working principle of these technologies is to promote controlled mixing of diluted and concentrated solutions by means of solvent flow, as in case of PRO, or of solute flow, as in the case of RED, CapMix, MEB, and NB. These systems are detailed ahead.

The PRO system was first described in 1954..$^{24,25}$ This system is based on the difference between the osmotic pressure $(\Delta \pi)$ of solutions of different concentrations, separated by semipermeable membranes. This difference in osmotic pressure is used to convert SGE into useful work. In the PRO system, the solvent is transported through a semipermeable membrane that blocks the solute and controls mixing of the diluted and the concentrated solutions (Figure 2a). An osmotic pressure gradient arises in the membrane due to the difference in the chemical potentials of the two solutions. This gradient promotes solvent flow from the diluted to the concentrated solution. Mechanical work originates from volume expansion of the pressurized concentrated solution (Figure $2 b$ ). To perform electrical work, a hydroturbine can be used to accomplish depressurization. ${ }^{18}$ Besides being an environmentally friendly technology, the PRO system continues to attract attention mainly because the world osmotic energy is estimated to be in the order of 1750-2000 TWh per year, which could be improved if we consider brine and brackish. ${ }^{15}$

In 1954, Pattle ${ }^{19}$ was the first to introduce the idea that the mixture of a pure solute with a solution constitutes an energy source. In that study, the author derived energy from osmotic pressure and solvent volume. The authors hypothesized and later confirmed that SGE could be converted by using alternate acid and basic membranes with a flow of diluted and concentrated saline passing between them. After 94 membranes were placed in a hydroelectric pile, the system produced a potential difference of $3.1 \mathrm{~V}$ or $15 \mathrm{~mW}$.
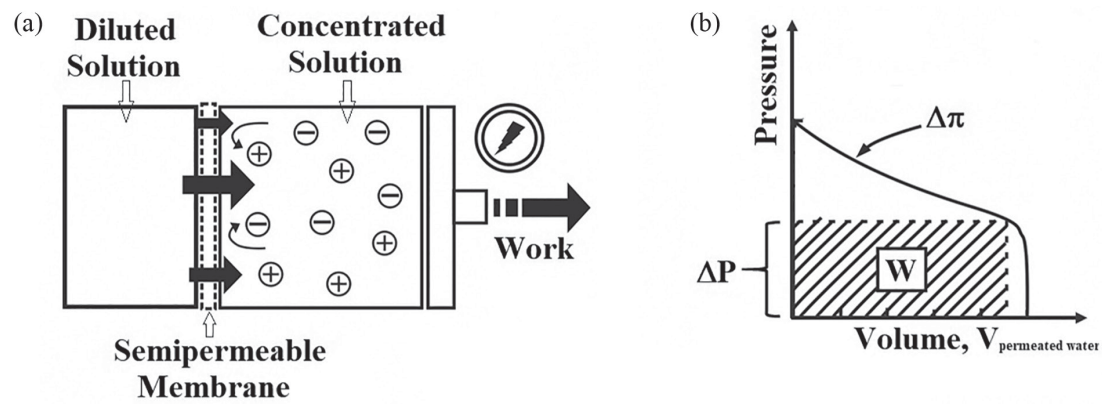

Figure 2. (a) Representation of a PRO cell; (b) representation of the work obtained from volume expansion of the concentrated solutions under constant pressure. Adapted from Yip et al. ${ }^{18}$

Diluted Solution Concentrated Solution

(a)

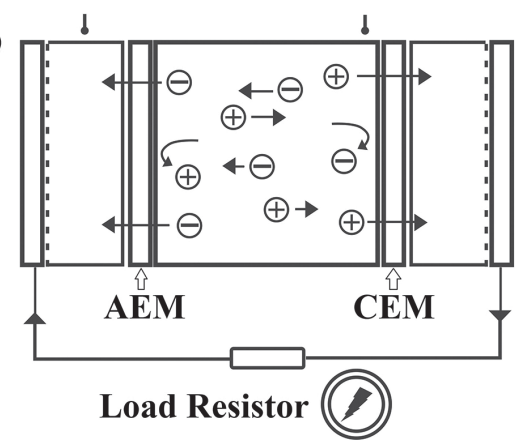

(b)

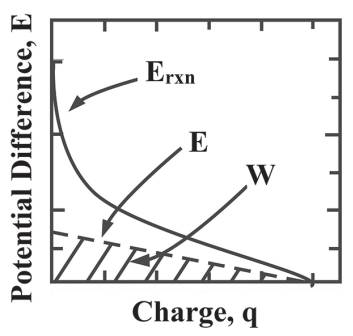

Figure 3. (a) Representation of a RED cell; (b) representation of the work extracted from capacitor discharge. Adapted from Yip et al. ${ }^{18}$ 
In a RED cell, a cation exchange membrane (CEM) and an anion exchange membrane (AEM) alternately separate the diluted and the concentrated solutions (Figure 3a). The electromotive force $\left(\mathrm{E}_{\mathrm{rxn}}\right)$ for selective ion flow through the ion exchange membranes (IEM) is generated by the difference in the chemical potential between the ions on each side of the membrane, which produces an electric potential difference. Simultaneous cation and anion transport in opposite directions maintains electroneutrality. The capacitive electrodes convert the ionic current into electric current at the end of the cell series, to produce electrical work. ${ }^{16}$

Both the PRO and the RED systems are based on membranes..$^{12}$ In the first case, solvent transport underlies controlled mixing of the solutions, whereas the mixing process depends on the solute transport in the second case. Therefore, membrane efficiency, cost, and lifetime are limiting factors when it comes to implementing these technologies on a large scale. ${ }^{15}$

\section{Capacitive Mixing}

Although PRO and RED are currently the most explored technologies for SGE storage, Brogioli et al. ${ }^{26,27}$ proposed an alternative system where a pair of porous electrodes is alternately immersed into diluted and concentrated solutions and acts as electric double-layer capacitors. This system is called capacitive mixing, and its working principle is based on the four-step cycle illustrated in Figure 4a. In step 1, an external power source charges the electrode, to promote ion adsorption from the concentrated solution onto the porous electrode surface and to keep the electric double layer (EDL) electroneutrality. In step 2, the circuit is open, and the concentrated solution is exchanged for the diluted solution. This solution exchange lowers the ionic strength and thickens the EDL. Considering that the ionic charge in the capacitive electrodes remains constant, EDL expansion occurs as its capacitance decreases and as the cell electric potential increases. ${ }^{22,28-31}$ During step 3, the circuit is closed: ions trapped in the EDL diffuse to the diluted solution, to culminate in controlled mixing. Ion flow from the EDL to the solutions and electron flow through the external circuit happen simultaneously, to produce electrical work. Finally, the circuit is open in step 4: the diluted solution is exchanged for a concentrated solution, and the cycle restarts.

Because the discharge process potential is higher (more positive) than the charge process potential, the electrical work produced in step 3 is higher than the energy consumed in step 1, which enables energy harvesting after a full cycle. Energy storage after a cycle is equal to the area between the charge/discharge curves or the line integral in Figure $4 b^{32}$

\section{Mixing Entropy Batteries}

The technical challenges arising in the CapMix system, such as high sensitivity to impurities and dissolved oxygen, stem from the use of activated carbon electrode, which results in EDL self-discharge. ${ }^{26}$ Some alternatives to improve the energy conversion efficiency in these systems have been proposed, e.g., electrode modification with membranes and electrodes containing nanosized pores. ${ }^{33,34}$

La Mantia et al. ${ }^{17}$ replaced capacitive electrodes with electrodes that involve faradaic reactions in the charge storage process, to create the system called mixing entropy batteries. Controlled mixing in MEB is similar to controlled mixing in CapMix. The difference lies in the use of insertion

\section{Step 3 Discharge}

(a) Concentrated Solution (CS)

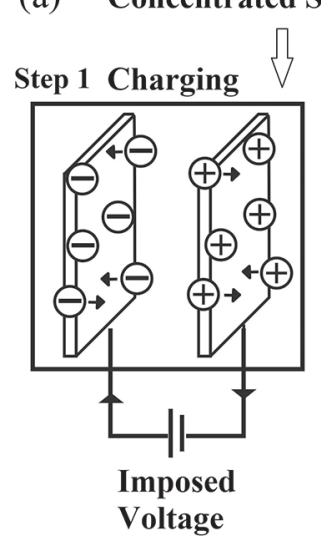

Step 2 Open circuit CS to DS

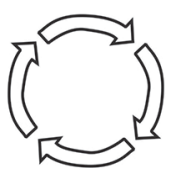

Step 4 Open circuit DS to CS Diluted Solution (DS) (b)

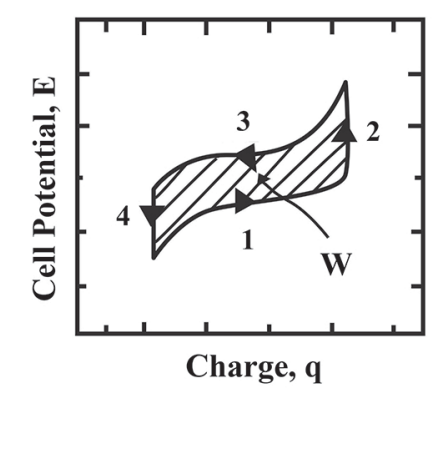

Figure 4. (a) Representation of the CapMix system working principle; (b) schematic representation of the extracted work after a full charge/discharge cycle. Adapted from Yip et al. ${ }^{18}$ 
electrodes for cations and anions that are charged and discharged in solutions of different salinity. In the first MEB cell described by La Mantia et al. ${ }^{17}$ an electrode consisting of $\mathrm{MnO}_{2}$ and a silver wire were used as the positive and the negative electrodes, respectively. Figure 5 shows the MEB operating cycle in these conditions: the charge process occurs in $0.024 \mathrm{M} \mathrm{NaCl}$ aqueous solution, whereas the discharge process takes place in $0.6 \mathrm{M} \mathrm{NaCl}$ aqueous solution.

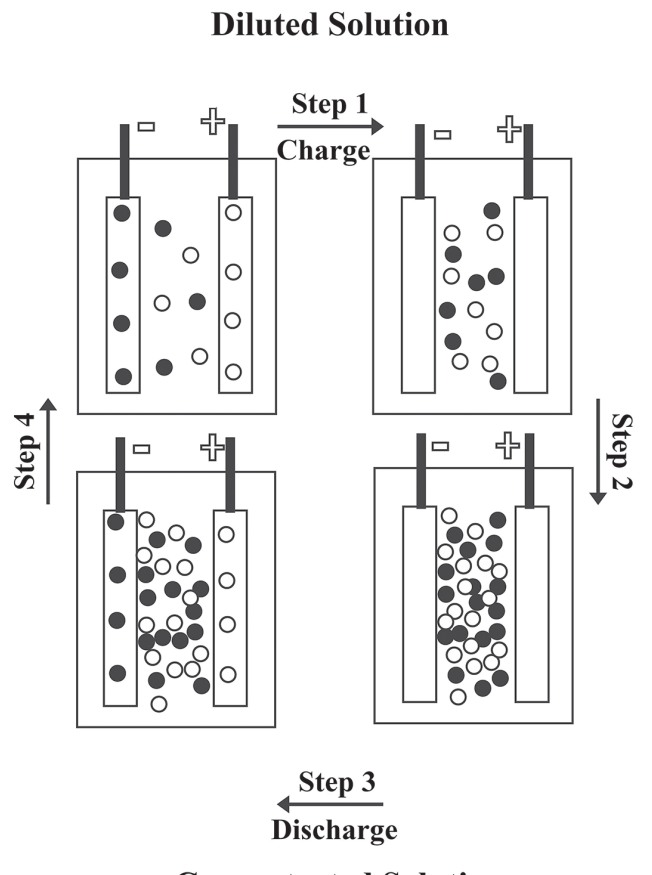

Concentrated Solution

Figure 5. Schematic representation of the MEB operating cycle.

When the system is discharged, sodium and chloride ions are inserted in the electrodes. The charge process happens in a solution with low electrolyte concentration, and the ions migrate and diffuse from the electrodes to the solution (step 1). After the charge process is complete, the diluted solution is exchanged for a concentrated solution (step 2). Then, during the discharge process in the concentrated solution, the ions are electro-inserted in the electrodes (step 3). Finally, the concentrated solution is exchanged for the diluted solution (step 4). Solutions with different $\mathrm{NaCl}$ concentrations $(0.024$ and $0.6 \mathrm{M})$ simulate freshwater and seawater, respectively. Figure 6 depicts the potential variation as a function of the charge involved in the cycle.

The potential gain provided by MEB is approximately three times higher than the potential gain provided by capacitive materials. ${ }^{17}$ Despite this advantage, this new technology is in its early stages, and only a few scientific papers have dealt with this topic. ${ }^{17,35-38}$

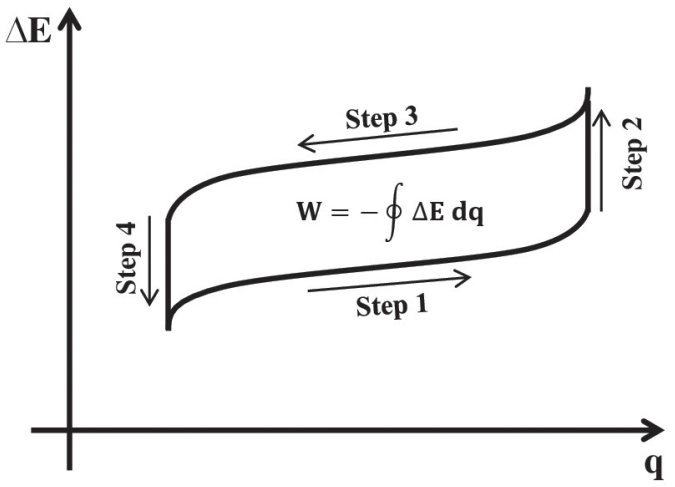

Figure 6. Schematic representation of the potential variation as a function of charge in MEB. The extracted work is given by the line integral of the cycle. Adapted from La Mantia et al. ${ }^{17}$

\section{Neutralization Batteries (or an Acid-Base Machine)}

Considering the ionic gradients originating from anthropogenic factors, an extension of the MEB concept could be applied to harvest energy during treatment of acidic wastewater and sewage, among other effluents. In this context, our group has recently proposed a new electrochemical system designated as neutralization batteries, which uses the change in partial entropy associated with proton activity variation during acidic solution neutralization. ${ }^{23}$

Similarly to CapMix and MEB, the NB discharge process is spontaneous and happens at a more positive voltage than the charge process, which is nonspontaneous. Energy conversion to work stems from controlled mixing between a solution containing high proton concentration (or low $\mathrm{pH}$ values) and a solution containing low proton concentration (or high $\mathrm{pH}$ values). ${ }^{23,39}$

$\mathrm{NB}$ can be understood as an idealized acid-base machine, which is similar to the concept of thermal machines. ${ }^{40} \mathrm{In}$ an ideal acid-base machine, matter flows between the acidic and the basic reservoirs, to provide maximum work. Figure 7 shows a schematic representation of the working principle of this idealized machine. This electrochemical system operates between an acidic and a basic reservoir in four stages: two reversible buffered isothermal stages and two open stages for the acidic and basic solutions to enter the system. The machine also contains two insertion electrodes: one is selective for proton insertion, whereas the other does not allow proton insertion.

Initially, an acidic solution is injected into the cell (step 1). Then, protons are electro-inserted in the selective electrode, and other ionic species are electro-inserted in the opposite electrode (step 2). The base is then injected into the cell (step 3). Finally, protons are electro-deinserted from the selective electrode, and the other ionic species are electro- 
deinserted from the opposite electrode. The neutralized solution is discharged into a suitable environment, and another acidic solution is injected into the cell, to restart the cycle.

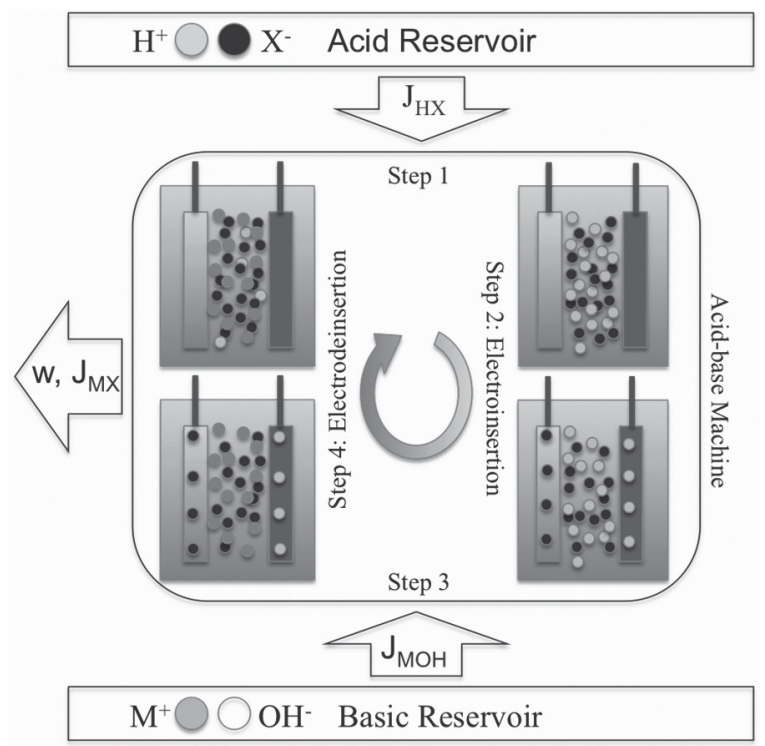

Figure 7. Schematic representation of the NB operating cycle. Adapted from Morais et al. ${ }^{40}$

\section{Thermodynamic Formalism for the Acid- Base Machine}

Machine efficiency as well as maximum produced work can be estimated by admitting that $\mathrm{M}_{1}$ is a negative insertion electrode that is selective for protons $\left(\mathrm{H}^{+}\right)$, whereas $\mathrm{M}_{2}$ is a positive insertion electrode that is selective for anions $\left(\mathrm{X}^{-}\right)$. In the presence of an external power source, the following nonspontaneous processes initially remove protons from the acidic solution:

$\mathrm{M}_{1}+\mathrm{H}^{+}+\mathrm{e}^{-} \rightarrow \mathrm{M}_{1} \mathrm{H}$
$\mathrm{M}_{2}+\mathrm{X}^{-} \rightarrow \mathrm{M}_{2} \mathrm{X}+\mathrm{e}^{-}$

Spontaneous processes occur with subsequent addition of base to the electrochemical cell:

$\mathrm{M}_{1} \mathrm{H} \rightarrow \mathrm{M}_{1}+\mathrm{H}^{+}+\mathrm{e}^{-}$

$\mathrm{M}_{2} \mathrm{X}+\mathrm{e}^{-} \rightarrow \mathrm{M}_{2}+\mathrm{X}^{-}$

For the cell reaction, one can equate the electrochemical potential of products and reagents to associate proton activity $\left(\mathrm{a}_{\mathrm{H}^{+}}\right)$, anion activity $\left(\mathrm{a}_{\mathrm{x}^{-}}\right), \mathrm{M}_{1}\left(\mathrm{a}_{\mathrm{M}_{1}}\right), \mathrm{M}_{1} \mathrm{H}\left(\mathrm{a}_{\mathrm{M}_{1} \mathrm{H}}\right)$, $\mathrm{M}_{2}\left(\mathrm{a}_{\mathrm{M}_{2}}\right)$, and $\mathrm{M}_{2} \mathrm{X}\left(\mathrm{a}_{\mathrm{M}_{2} \mathrm{X}}\right)$ with the electromotive force $\left(\mathrm{E}_{\mathrm{rxn}}\right)$ in the acidic and in the neutral solutions, as shown in equations 7 and 8, respectively.

$$
\begin{aligned}
& \mathrm{E}_{\mathrm{rxn}}=\mathrm{E}_{\mathrm{rxn}}^{0}\left(\mathrm{~T}_{1}\right)-\frac{\mathrm{RT}_{1}}{\mathrm{~F}} \ln \left(\frac{\mathrm{a}_{\mathrm{M}_{1} \mathrm{H}}^{\mathrm{a}}}{\mathrm{a}_{\mathrm{M}_{1}}} \frac{\mathrm{a}_{\mathrm{M}_{2} \mathrm{X}}}{\mathrm{a}_{\mathrm{M}_{2}}^{a}} \frac{1}{\mathrm{a}_{\mathrm{H}^{+}}^{\mathrm{a}} \mathrm{a}_{\mathrm{X}^{-}}^{\mathrm{a}}}\right) \\
& \mathrm{E}_{\mathrm{rxn}}=\mathrm{E}_{\mathrm{rxn}}^{0}\left(\mathrm{~T}_{1}\right)+\frac{\mathrm{RT}_{1}}{\mathrm{~F}} \ln \left(\frac{\mathrm{a}_{\mathrm{M}_{1} \mathrm{H}}^{\mathrm{n}}}{\mathrm{a}_{\mathrm{M}_{1}}^{\mathrm{n}}} \frac{\mathrm{a}_{\mathrm{M}_{2} \mathrm{X}}^{\mathrm{n}}}{\mathrm{a}_{\mathrm{M}_{2}}^{\mathrm{n}}} \frac{1}{\mathrm{a}_{\mathrm{H}^{+}}^{\mathrm{n}} \mathrm{a}_{\mathrm{X}^{-}}^{\mathrm{n}}}\right)
\end{aligned}
$$

where $\mathrm{F}$ is the Faraday constant and $\mathrm{E}_{\mathrm{rxn}}^{0}$ is the standard electromotive force. The superscripts a and $\mathrm{n}$ represent the acidic and the neutral media, respectively. Equation 9 gives the total sum of the electromotive forces $\left(\mathrm{E}_{\mathrm{rxn}, \text { neut }}\right)$ of the spontaneous and nonspontaneous processes:

$$
\mathrm{E}_{\mathrm{rxn}, \text { neut }}=\frac{\mathrm{RT}_{1}}{\mathrm{~F}} \ln \left(\frac{\mathrm{a}_{\mathrm{H}^{+}}^{\mathrm{a}}}{\mathrm{a}_{\mathrm{H}^{+}}^{\mathrm{n}}} \frac{\mathrm{a}_{\mathrm{X}^{-}}^{\mathrm{a}}}{\mathrm{a}_{\mathrm{X}^{-}}^{\mathrm{n}}}\right)
$$

In this condition, the temperature $\left(T_{1}\right)$ is the same in both the spontaneous and the nonspontaneous processes. The anion activities can be canceled from equation 9 if we assume that the ionic strength remains constant during neutralization, and that the mean activity coefficients depend exclusively on the ionic strength according to Debye-Hückel law:

$$
\mathrm{E}_{\mathrm{rxnnn \text {neut }}}=\frac{\mathrm{RT}_{1}}{\mathrm{~F}} \ln \left(\frac{\mathrm{a}_{\mathrm{H}^{+}}^{\mathrm{a}}}{\mathrm{a}_{\mathrm{H}^{+}}^{\mathrm{n}}}\right)
$$

The efficiency of the idealized machine $\left(\varepsilon_{\text {neut }}\right)$ associated with the neutralization process can now be determined by introducing the concepts of work (w) and neutralization enthalpy $\left(\Delta \mathrm{H}_{\mathrm{r}}\right)$ :

$\varepsilon_{\text {neut }}=\frac{-\mathrm{w}}{\Delta \mathrm{H}_{\mathrm{r}}}=\frac{-\Delta \mathrm{G}}{\Delta \mathrm{H}_{\mathrm{r}}}=\frac{\mathrm{FE}_{\mathrm{rxn}}}{\Delta \mathrm{H}_{\mathrm{r}}}=\frac{\mathrm{RT}_{1} \ln \left(\frac{\mathrm{a}_{\mathrm{H}^{+}}^{\mathrm{a}}}{\mathrm{a}_{\mathrm{H}^{+}}^{\mathrm{n}}}\right)}{\Delta \mathrm{H}_{\mathrm{r}}}$

We have considered the resulting solution in neutral medium due to the environmental preservation. However, the resulting solution $\mathrm{pH}$, the work, and the efficiency depend on the acid solution $\mathrm{pH}$ and the amount of base added in this solution. If we admit that the acidic reservoir has unitary activity, efficiency can be expressed as a function of the resulting solution $\mathrm{pH}$ only:

$\varepsilon_{\text {neut }}=\frac{2.3 \mathrm{RTpH}}{\Delta \mathrm{H}_{\mathrm{r}}}$

Efficiency as defined in equation 12 is a function of the hydrogen potential and does not depend on the electrodes or on the electrolyte because this machine operates in an idealized cycle. Hence, it is possible to determine the 
hydrogen potential on a purely electrical and mechanical basis because the produced electrical work can be transferred to the neighborhood.

Some small pH deviations occur during the nonbuffered charge/discharge process in a practical system. The ratio between the number of electroactive sites in the host matrices and the quantity of protons in the electrolyte solution determines these variations. Nevertheless, these $\mathrm{pH}$ oscillations do not affect the maximum work produced by the system: in these conditions, this work corresponds to a state function and does not consider the heat released under the reversible electrochemical processes, i.e., this work depends only on the initial and on the final states.

Machine efficiency can increase if heat release during the neutralization process occurs adiabatically (step 3 ). In this condition, the temperatures of the nonspontaneous $\left(\mathrm{T}_{1}\right)$ and of the spontaneous $\left(\mathrm{T}_{2}\right)$ processes will be different: $\mathrm{T}_{2}>\mathrm{T}_{1}$ when $\mathrm{E}_{\mathrm{rxn}}\left(\mathrm{T}_{2}\right)>\mathrm{E}_{\mathrm{rxn}}\left(\mathrm{T}_{1}\right)$. The new efficiency can be calculated with the aid of equation 13 :

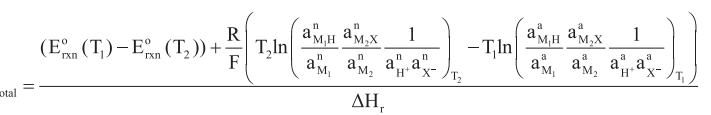

\section{Electrode Materials and Electrochemical Properties}

The materials used in MEB and NB do not need to exhibit the same electrochemical properties as the electrodes of secondary batteries or pseudocapacitors. MEB and NB voltage during the discharge process is not essential for their good performance because the electrical work depends on the potentials involved in both the charge and discharge cycles. Hence, if the potential difference between the electrodes of these batteries is low but the difference between the charge and discharge potentials is high (Figure 6), energy harvesting is high at the end of the cycle. On the other hand, the small energy loss associated with overpotentials, the absence of irreversible parallel reactions, and the potential variation as a function of the electrolytic solution concentration are relevant factors when choosing electrodes. Consequently, insertion materials that do not exhibit high power densities when they are used in batteries (low voltage and high molecular weight) can be suitable for MEB and NB. Given that these electrode materials have high charge capacity and practical reversibility, they can be an alternative to these batteries.

For a material to be used in these types of batteries, it must have the following basic characteristics and properties: $(i)$ the material must be electroactive, and its structure must allow chemically reversible and selective ion insertion/deinsertion; (ii) the host matrices must be highly selective for the ion during insertion/deinsertion. Therefore, ionic species with different charges must intercalate in different electrodes in the battery; (iii) the material structure must be minimally altered after the charge/discharge cycle to prevent the capacity from dropping and to increase battery durability; (iv) the electrode must have high ion storage capacity to maximize energy conversion per cycle; (v) the electrode must have high ionic mobility to reduce the overpotentials associated with mass transport; ( $v i)$ the host matrix must present high conductivity or alternative paths for electron transport within the matrix, to reduce ohmic drops in the electrode; and (vii) the material must be inexpensive and non-toxic.

We discuss some examples of materials used to assemble MEB and NB below.

\section{Prussian Blue Analogues}

Prussian Blue (PB) is an extensively investigated coordination compound with well-known physicochemical properties. ${ }^{41,42}$ This inorganic polymer belongs to the class of materials denominated polycyanometallates, which are normally little soluble in aqueous medium. Two known PB forms exist, $\mathrm{KFe}\left[\mathrm{Fe}(\mathrm{CN})_{6}\right]$ and $\mathrm{Fe}_{4}\left[\mathrm{Fe}(\mathrm{CN})_{6}\right]_{3}$, which consist of $\mathrm{Fe}^{\mathrm{III}}-\mathrm{NC}-\mathrm{Fe}^{\mathrm{II}}$ chains in a cubic lattice. ${ }^{41}$ Low charge transfer resistance and high potassium ion diffusion coefficient (considering that the ionic flux in the solid host matrices is in the order of $10^{-9} \mathrm{~cm}^{2} \mathrm{~s}^{-1}$ ) ensure low overpotentials during PB charge/discharge. ${ }^{43}$ Moreover, these properties allow one to obtain a specific capacity close to the theoretical value $\left(87.36 \mathrm{mAh} \mathrm{g}^{-1}\right)$ in a potential window that does not involve hydrogen or oxygen evolution, which increases the PB chemical reversibility when it is used as electrode in secondary batteries. ${ }^{44}$

The channels present in the PB structure allow potassium ions (radius smaller than $1.5 \AA$ ) to intercalate during the charge compensation mechanism in aqueous medium. According to the Stokes law and the limit mobility, solvated $\mathrm{Li}^{+}, \mathrm{Na}^{+}$, and $\mathrm{K}^{+}$ions in aqueous medium have radii equal to $2.37,1.83$, and $1.25 \AA$, respectively, which hinder their intercalation into the PB structure. In fact, the reversible insertion capacity of these ions is inversely proportional to their radii, which limits the use of $\mathrm{PB}$ in MEBs. ${ }^{45,46}$

Modifications to the PB structure aim to increase its stability during the electro-insertion of other cations and to control and/or modify several of its properties. The resulting compounds, denominated Prussian Blue analogues (PBA), have different applications.

PBA materials are a family of compounds with general formula $\mathrm{A}_{\mathrm{x}} \mathrm{M}\left[\mathrm{Fe}(\mathrm{CN})_{6}\right]_{z}$, where $\mathrm{A}$ is an alkaline cation and 
$\mathrm{M}$ is a transition metal. ${ }^{47-51}$ In contrast to PB host matrices, PBAs tend to accommodate other cations effectively during the electro-insertion process because they have a larger open-channel network. ${ }^{52,53}$ In particular, $\mathrm{Li}^{+}, \mathrm{Na}^{+}, \mathrm{Mg}^{2+}$, and $\mathrm{NH}_{4}{ }^{+}$intercalation into these matrices affords electrodes that have been explored in batteries in both aqueous and organic media. ${ }^{54-56}$

Nickel(II) hexacyanoferrate (NiHCF) and copper(II) hexacyanoferrate $(\mathrm{CuHCF})$ are examples of PBAs. $\mathrm{CN}$ bridges connect iron ions and the $\mathrm{M}$ metal $\left(\mathrm{M}=\mathrm{Ni}^{2+}\right.$, $\mathrm{Cu}^{2+}$ ) in NiHCF and in $\mathrm{CuHCF}$, to create a face-centered cubic structure. In these coordination compounds, the $\mathrm{Ni}^{2+}$ and $\mathrm{Cu}^{2+}$ ions occupy the crystalline network sites where $\mathrm{PB}$ is replaced with high-spin iron atoms. Each iron atom coordinates to six nitrogen atoms, to produce an open channel network along with three crystallographic axes that allow insertion of hydrated cations. Furthermore, the mechanic stress generated by insertion of hydrated alkaline ions is low $(<1 \%)$, so these electrodes can be used in several charge/discharge cycles without having their storage capacity significantly reduced..$^{54}$

The following equation represents the electrochemical reaction involved in the charge/discharge processes of these two analogues: ${ }^{57}$

$\mathrm{A}_{\mathrm{x}} \mathrm{M}_{\mathrm{y}}\left[\mathrm{M}^{\prime(\mathrm{III})}(\mathrm{CN})_{6}\right]_{\mathrm{z}}+\mathrm{a}\left(\mathrm{A}^{+}+\mathrm{e}^{-}\right) \rightleftharpoons \mathrm{A}_{(\mathrm{x}+\mathrm{a})} \mathrm{M}_{\mathrm{y}}\left[\mathrm{M}^{\prime(\mathrm{II})}(\mathrm{CN})_{6}\right]_{\mathrm{a}}\left[\mathrm{M}^{\prime(\mathrm{III})}(\mathrm{CN})_{6}\right]_{(\mathrm{z}-\mathrm{a})}$

where $\mathrm{A}^{+}$is the alkaline ion, $\mathrm{M}$ corresponds to the $\mathrm{Ni}^{2+}$ or to the $\mathrm{Cu}^{2+}$ ion, and $\mathrm{M}^{\prime}$ corresponds to another transition metal ion.

At $10 \mathrm{mg} \mathrm{cm}^{-2}$, NiHCF nanoparticles exhibit a specific capacity of $59 \mathrm{mAh} \mathrm{g}^{-1}$ for a $\mathrm{C} / 6$ rate $\left(60 \mathrm{~mA} \mathrm{~g}^{-1}\right.$ was

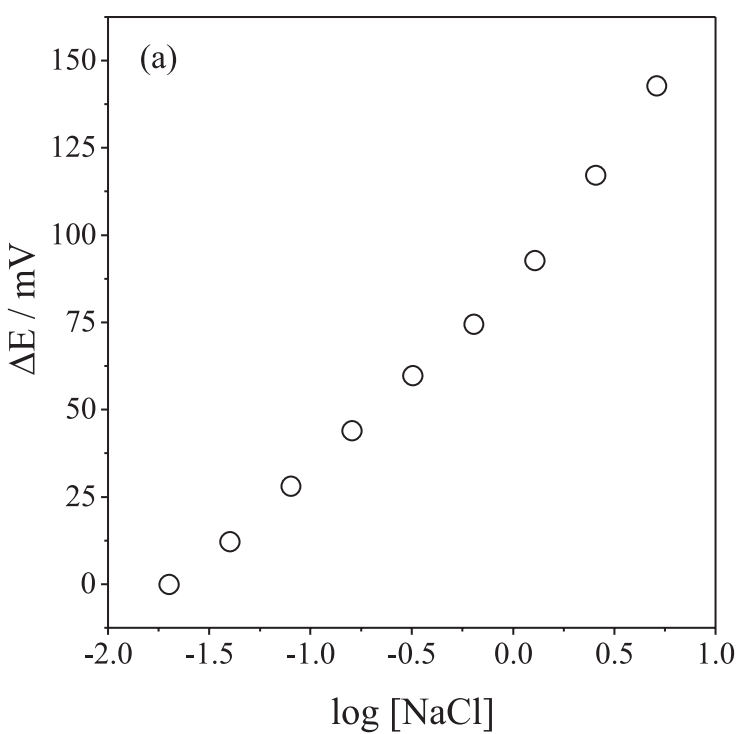

defined as $1 \mathrm{C}$ rate) in both $1 \mathrm{M} \mathrm{NaNO}_{3}$ and $1 \mathrm{M} \mathrm{KNO}_{3}$ aqueous solutions. Moreover, their capacity decreases by $13.5 \%$ when the $\mathrm{C}$ rate increases to $8.3 \mathrm{C}$ under several charge/discharge cycles. The specific capacity is approximately $51 \mathrm{mAh} \mathrm{g}^{-1}$ before and after 5000 cycles under a current close to $3000 \mathrm{~mA} \mathrm{~g}^{-1} .{ }^{54}$ On the other hand, CuHCF nanoparticles retain $99 \%$ of their capacity after 1000 cycles..$^{50}$ Based on the charge/discharge curves, overpotentials are low at $0.83 \mathrm{C}$ rate, which demonstrates low irreversibility. ${ }^{58}$ Added to these properties is the fact that the potential of modified PBA electrodes generally varies $59 \mathrm{mV}$ per logarithm unit of the alkaline ion concentration. ${ }^{59,60} \mathrm{NiHCF}$ and $\mathrm{CuHCF}$ display properties that are worth exploring in MEB.

In fact, Gomes et al. ${ }^{61}$ used thin NiHCF films to check the applicability of PBA in MEB. The average anodic and cathodic peak potentials relative to the potential measured for the electrolytic $20 \mathrm{mM} \mathrm{NaCl}$ solution as a function of the molar concentration logarithm demonstrated that it is possible to use this electrode to convert energy from a highly saline water source (Figure 8a): the authors extracted $12.4 \mathrm{~kJ}$ per mol of sodium ion after a charge/ discharge cycle, which is equivalent to the area between the discharge curve in a $3.0 \mathrm{M} \mathrm{NaCl}$ aqueous solution and the charge curve in a $20 \mathrm{mM} \mathrm{NaCl}$ aqueous solution (Figure 8b).

\section{Polypyrrole (PPy)}

Conductive polymers are a class of materials with a wide range of applications and which have attracted significant scientific interest. ${ }^{62}$ In the early 1970 s, it was accidentally

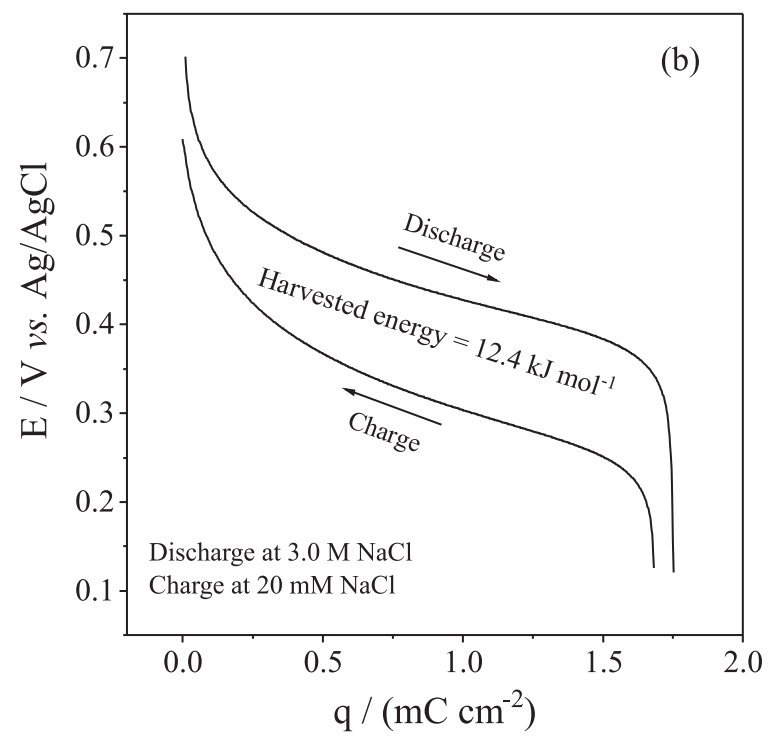

Figure 8. (a) Average anodic and cathodic peak potentials as a function of the $\mathrm{NaCl}$ molar concentration logarithm; (b) area between charge and discharge curves (at $10 \mu \mathrm{A} \mathrm{cm}^{-2}$ ) for the NiHCF film allowed an electrochemical energy extraction of $12.4 \mathrm{~kJ}$ per mol of sodium ion per cycle. Adapted from Gomes et al. ${ }^{61}$ 
discovered that metals and polyacetylene doped with iodine display similar conductive properties. Since then, a considerable quantity of new conductive polymers have been synthesized. ${ }^{63}$ During the chemical or electrochemical synthesis of conductive polymers, the monomer units form covalent bonds that invariably lead to conjugated chains where double and single bonds alternate, to afford a system where $\pi$-type electrons are delocalized along the entire chain. In contrast to strong $\sigma \mathrm{C}-\mathrm{C}$ bonds, the low bond energy of delocalized $\pi$ electrons allows their excitation to empty orbitals with close energy, which underlies the semi-conductive character of polymers. The conductivity of these conjugated polymers can be enhanced by oxidation of their chains. Oxidation/reduction processes, also known as doping/de-doping, are commonly accompanied by an ion flow in the electrode/solution interface, which maintains the electroneutrality of the polymer matrix.

Due to its wide potential window, mechanical properties, aqueous insolubility, and high electron conductivity (ca. 100-10,000 S m$^{-1}$ ), polypyrrole (PPy) is one of the most studied electronic conducting polymers. ${ }^{64-66}$ PPy films can be obtained by chemical or electrochemical polymerization, and the properties of the resulting films depend on synthesis parameters such as concentration, substrate, dopant, oxidant, current, and potential, among others. Moreover, PPy films with distinct properties can be achieved through the synthesis of PPy films in the composite form.

As a result of the formation of polarons $\left(\mathrm{PPy}^{+}\right)$and bipolarons $\left(\mathrm{PPy}^{2+}\right)$ in the polymeric chains, anions can be electro-inserted/electro-deinserted into the PPy film during the charge compensation mechanism:

$$
\begin{aligned}
& \mathrm{PPy}^{+} \mathrm{X}^{-}+\mathrm{e}^{-} \underset{\text { doping }}{\stackrel{\text { de-doping }}{\rightleftharpoons}} \mathrm{PPy}+\mathrm{X}^{-} \\
& \mathrm{PPy}^{2+} \mathrm{X}_{2}^{-}+2 \mathrm{e}^{-} \underset{\text { doping }}{\stackrel{\text { de-doping }}{\rightleftharpoons}} \mathrm{PPy}+2 \mathrm{X}^{-}
\end{aligned}
$$

where $\mathrm{X}^{-}$is the anion, and PPy symbolizes a chain segment of polypyrrole..$^{67,68}$

An electrode consisting of silver particles dispersed in PPy $(\mathrm{Ag} / \mathrm{PPy})$ was prepared and used as the negative electrode in a MEB system. ${ }^{61} \mathrm{~A}$ full cell consisting of $\mathrm{NiHCF}$ (positive) and Ag/PPy (negative) electrodes afforded $16.8 \mathrm{~kJ}$ per mol of sodium ion for each electrochemical cycle as demonstrated by charge/ discharge curves (Figure 9). The negative electrode removed and provided chloride anions during the oxidation and the reduction processes, respectively. The electrode redox potential also changed when the anion concentration varied. This phenomenon also increased the energy harvested after the charge (low concentration)/ discharge (high concentration) cycle when Ag/PPy was employed as the negative electrode.

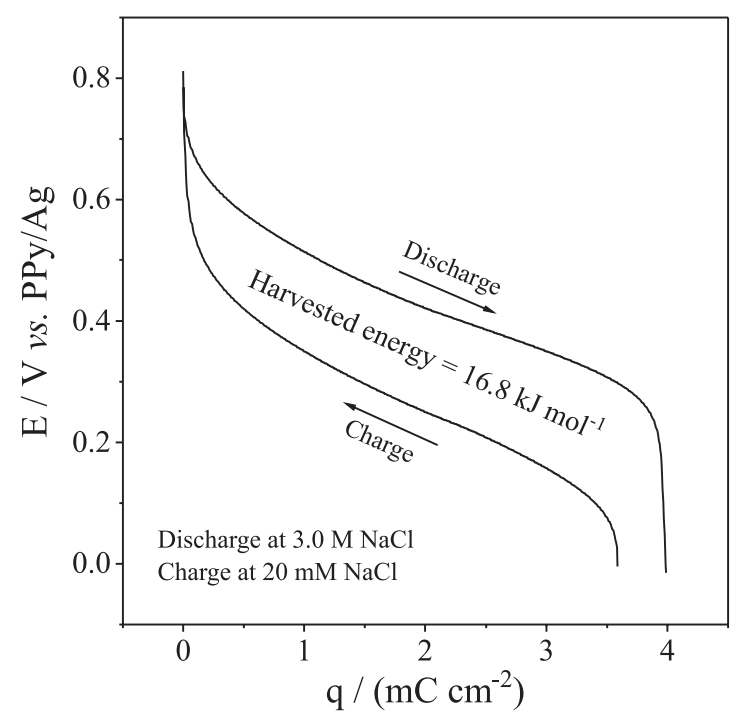

Figure 9. By using $\mathrm{NiHCF}$ as the positive electrode and $\mathrm{Ag} / \mathrm{PPy}$ as the negative electrode for the full cell, it was possible to extract $16.8 \mathrm{~kJ} \mathrm{~mol}^{-1}$ per cycle from the charge/discharge curves at $10 \mu \mathrm{A} \mathrm{cm} \mathrm{cm}^{-2}$. Adapted from Gomes et al. ${ }^{61}$

\section{Phosphomolybdic Acid}

Polyoxometallates (POM) are an important class of materials and have been the object of supramolecular inorganic chemistry studies. These compounds consist of anionic transition metal molecular oxides where the transition metals present high oxidation states. ${ }^{69}$ This configuration has attracted the interest of different scientific areas and can be applied in catalysis,${ }^{70}$ energy conversion, ${ }^{71}$ and molecular electronics. ${ }^{72}$ The basal structure of these materials consists of a tetrahedral nucleus surrounded by twelve $\mathrm{MO}_{6}$ octahedral units that share their edges and vertices. When the central octahedron consists of $\mathrm{PO}_{4}$ units and molybdenum is the transition metal, the resulting POM is named phosphomolybdic acid (PMA). PMA exhibits a well-defined structure. It undergoes reversible multiple-electron electrochemical processes associated with disproportionation reactions. Equations 17, 18, and 19, which involve the reduction states I, III, and V, respectively, allow fast proton electro-insertion during the PMA electrochemical reaction. ${ }^{73}$ Furthermore, PMA is highly stable in acid medium and exhibits high negative charge density. However, the high solubility of PMA and other polyoxometallates prevents their direct application in solid-state electrochemistry. The most common strategy to overcome this problem is to prepare organic-inorganic hybrid composites. ${ }^{70,71,74}$ 

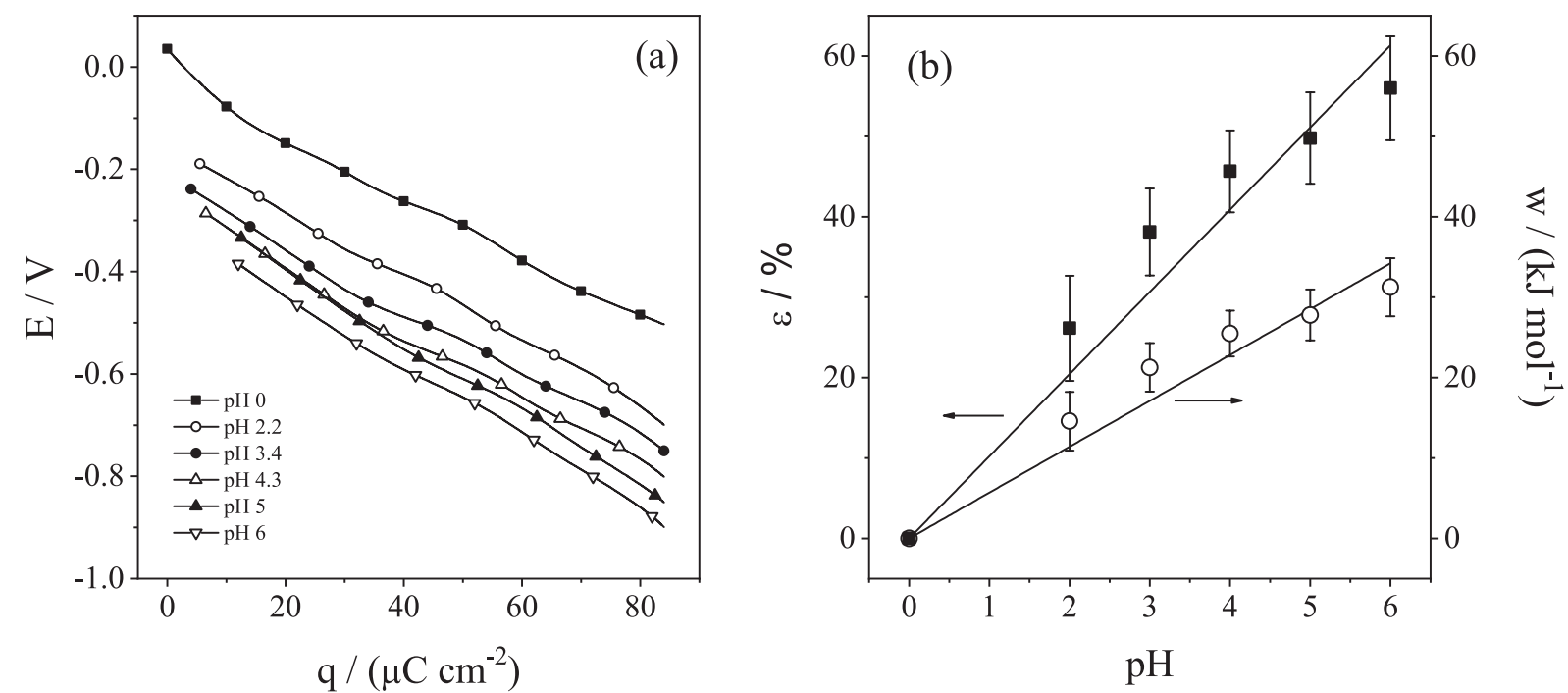

Figure 10. (a) Electroreduction curves, at $\mathrm{pH} 0$, and electrooxidation curves, at several $\mathrm{pH}$ values, of the PMA/PAH/PEDOT-PSS host matrix with $\mathrm{j}=5 \mu \mathrm{A} \mathrm{cm}^{-2}$; (b) theoretical (一) and experimental efficiency (口) and work $(\mathrm{O})$ as a function of the resulting solution pH. Adapted from Morais et al. . $^{40}$

$\mathrm{PMo}_{12} \mathrm{O}_{40}{ }^{3-}+2 \mathrm{e}^{-}+2 \mathrm{H}^{+} \leftrightarrows \mathrm{H}_{2} \mathrm{PMo}_{10}{ }^{\mathrm{VI}} \mathrm{Mo}_{2}{ }^{\mathrm{V}} \mathrm{O}_{40}{ }^{3-}$

$\mathrm{H}_{2} \mathrm{PMo}_{10}{ }^{\mathrm{VI}} \mathrm{Mo}_{2}{ }^{\mathrm{V}} \mathrm{O}_{40}{ }^{3-}+2 \mathrm{e}^{-}+2 \mathrm{H}^{+} \leftrightarrows$

$$
\mathrm{H}_{4} \mathrm{PMo}_{8}{ }^{\mathrm{VI}} \mathrm{Mo}_{4}{ }^{\mathrm{V}} \mathrm{O}_{40}{ }^{3-}
$$

$$
\mathrm{H}_{4} \mathrm{PMo}_{8}{ }^{\mathrm{VI}} \mathrm{Mo}_{4}{ }^{\mathrm{V}} \mathrm{O}_{40}{ }^{3-}+2 \mathrm{e}^{-}+2 \mathrm{H}^{+} \underset{5}{\stackrel{\mathrm{H}}{\leftrightarrows} \mathrm{PMo}_{6}{ }^{\mathrm{VI}} \mathrm{Mo}_{6}{ }^{\mathrm{V}} \mathrm{O}_{40}{ }^{3-}}
$$

To reduce the solubility of phosphomolybdic acid in aqueous medium, Morais et al..$^{40}$ coupled PMA with the polymers poly(allylamine) (PAH) and poly(3,4-ethylenodioxythiophene)-poly(styrenesulfonate) (PEDOT-PSS) by the layer-by-layer (LbL) method, to obtain self-assembled films. Electrostatic interactions between the PMA oxygen atoms, the PAH protonated amine groups, and the PSS sulfonic groups allowed the film to grow. The high conductivity of PEDOT-PSS charge carriers, i.e., polarons, bipolarons, and free carriers, helped to reduce the overpotentials during the electroreduction/ electrooxidation processes. Additionally, the LbL method allowed film thickness control and electrode dimensioning, which promoted low diffusional and ohmic overpotential. Moreover, the intimate contact between the materials promoted by the LbL method elicited a synergistic effect that improved the specific capacity and ensured the practical reversibility of the electrochemical process. ${ }^{23,39,40}$

An experimental proof of concept of the acid-base machine was carried out by using a three-electrode cell consisting of PMA/PAH/PEDOT-PSS as the working electrode, a platinum sheet as the counter electrode, and an $\mathrm{Hg} / \mathrm{Hg}_{2} \mathrm{SO}_{4}$ electrode as the reference electrode. Figure 10a shows the electroreduction, at $\mathrm{pH} 0$, and the electrooxidation, at several $\mathrm{pHs}$, of the PMA host matrix in a process that simulated $\mathrm{H}_{2} \mathrm{SO}_{4}$ neutralization with $\mathrm{KOH}$. The areas between the curves were used to calculate the harvested energy, and efficiency was calculated with the aid of equation 12. The experimental values were close to the predicted values, as shown in Figure 10b. It was possible to store $31.2 \mathrm{~kJ}$ per mol of electro-inserted proton when the system operated between an acidic reservoir with $\mathrm{pH} 0$ and a resulting solution with $\mathrm{pH}$ 6; the efficiency was $56.3 \%$.

Figure 11 displays a diagram containing all the host matrix electroreduction/electrooxidation combinations, which was constructed to estimate an optimum $\mathrm{pH}$ range for application of the system. This diagram provided the experimental work produced by the acid-base machine in all studied conditions.

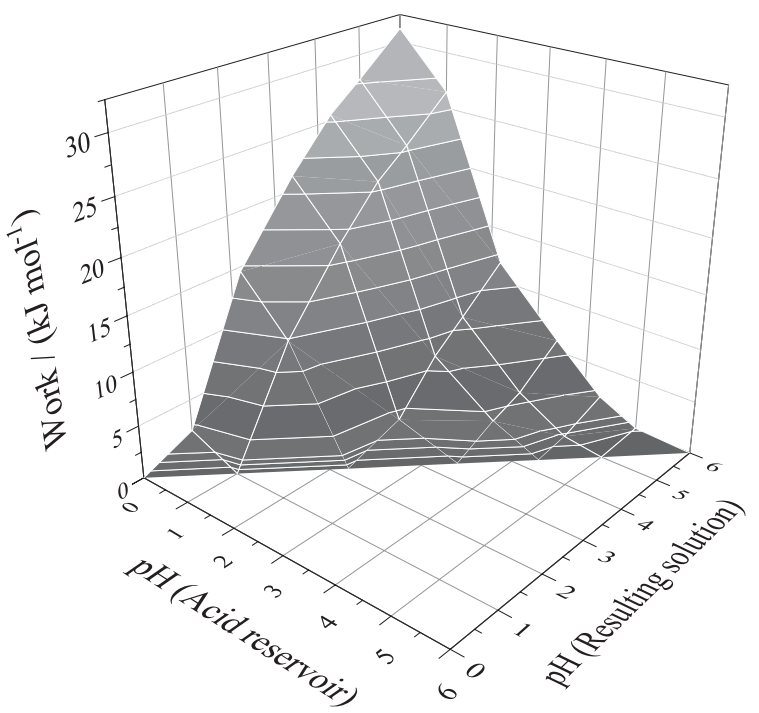

Figure 11. Work produced by the acid-base machine as a function of the $\mathrm{pH}$ of the acid reservoir and of the resulting solution. Adapted from Morais et al..$^{40}$ 


\section{Poly(3,4-ethylenodioxythiophene)}

PEDOT, a conducting polymer, is one of the most successful polythiophene derivatives. Its structure presents linear chains due to blockage of the 3,4 positions of the thiophene ring. PEDOT conductivity remains optimum due to continuous, uninterrupted $\pi$-conjugation. ${ }^{75,76}$

3,4-Ethylenedioxythiophene (EDOT) is the monomer unit of PEDOT. EDOT polymerization is one of the most common methods to obtain PEDOT films. This method requires a conducting substrate for film growth. Some aspects, like solvent, supporting electrolyte, electrode, polymerization potential, and applied electropolymerization method might have important effects on the film consisting of electropolymerized PEDOT; nevertheless, all these experimental conditions can be perfectly controlled..$^{75-77}$ PEDOT stands out among conducting polymers because it has high conductivity, approximately $500 \mathrm{~S} \mathrm{~cm}^{-1}$; it also presents good environmental stability, provides broad potential window, has a fast charge/ discharge process, and charge storage properties, which together increase the interest in supercapacitor materials. ${ }^{78}$ During the charge/discharge process, the PEDOT charge compensation mechanism occurs predominantly with the help of anions $\left(\mathrm{ClO}_{4}^{-}, \mathrm{NO}_{3}^{-}, \mathrm{SO}_{4}{ }^{2-}\right.$, and $\left.\left.\mathrm{BF}_{4}^{-}\right)\right)^{79}$

Aiming at its applications as the positive electrode in NB cells, an electro-synthesized PEDOT film was used to intercalate/deintercalate sulfate anions during the charge/ discharge processes; a PMA/PAH/PEDOT-PSS film was used as the negative electrode. ${ }^{40}$ In these experiments, a $0.05 \mathrm{M} \mathrm{H}_{2} \mathrm{SO}_{4}$ aqueous solution was neutralized with $\mathrm{KOH}$. For this cell, the charge process was performed at several $\mathrm{pHs}$, and the discharge process was carried out at $\mathrm{pH} 6$, as seen in Figure 12.

Table 1 lists the values obtained for this electrochemical configuration. The results are close to the results predicted by the thermodynamic formalism. The $\frac{\mathrm{w}}{\mathrm{C}_{\mathrm{b}}}$ ratio represents the relation between the produced work and the base concentration $\left(\mathrm{C}_{\mathrm{b}}\right)$, which provides an estimate for practical systems that consider the amount of base that should be used to neutralize the target acidic solution. This ratio might provide an insight into an optimum range for the

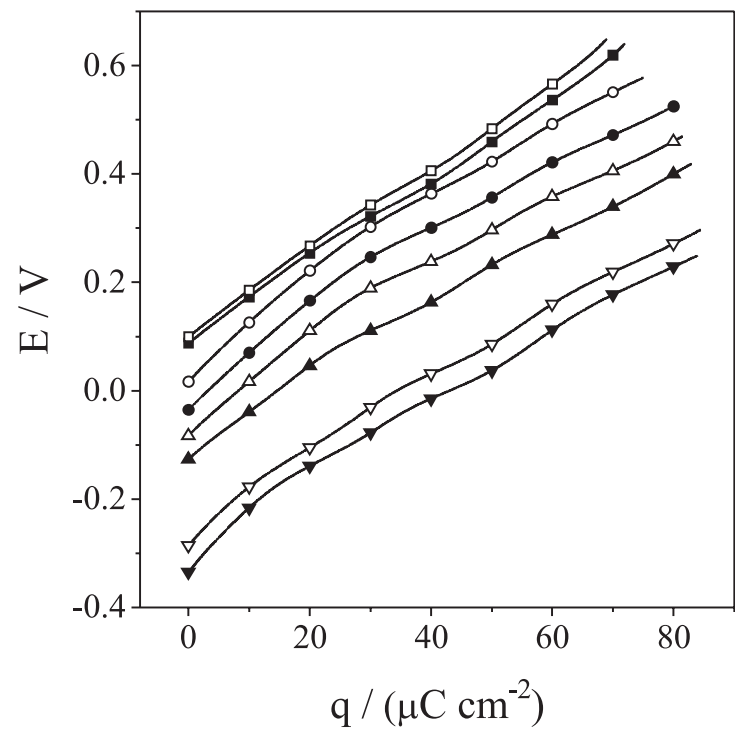

Figure 12. Charge/discharge curves for the acid-base machine consisting of PMA/PAH/PEDOT-PSS film and electro-synthesized PEDOT as the negative and the positive electrodes, respectively: charge at $\mathrm{pH} 0(\boldsymbol{\nabla})$, pH $1(\nabla), \mathrm{pH} 2.2(\mathbf{\Delta}), \mathrm{pH} 3.4(\triangle), \mathrm{pH} 4.3(\mathbf{O})$, and $\mathrm{pH} 5(\bigcirc)$ at $298 \mathrm{~K}$, and discharge at $\mathrm{pH} 6$ at $298 \mathrm{~K}(\square)$ and $318 \mathrm{~K}(\square) . \mathrm{j}=5 \mu \mathrm{A} \mathrm{cm}^{-2}$. Adapted from Morais et al. ${ }^{40}$

implementation of an electrochemical system that might be more profitable per volume of the solution.

As mentioned before, the heat released during the neutralization process could be used to improve the NB system performance. For this purpose, a discharge process was performed at $\mathrm{pH} 6$ and $318 \mathrm{~K}$, and the charge process was carried out at $\mathrm{pH} 6$ and $298 \mathrm{~K}$, to simulate the neutralization of $1.5 \mathrm{~mol} \mathrm{~L}^{-1}$ of protons in solutions and to promote a temperature rise of $20.1 \mathrm{~K}$ (Figure 12). These experimental conditions yielded $812 \mathrm{~J}$ per mol of electroinserted proton, which corresponded to $34.48 \%$ of the work expected from the Carnot cycle.

\section{Conclusions and Outlook}

We have discussed electrochemical systems that can harvest energy from salinity and proton gradients. Due to the tremendous energetic potential and the low environmental impact of salinity and proton gradient technologies, these technologies constitute an important strategy to diversify the world energy matrix. Natural

Table 1. Performed work, efficiency, and work per concentration of base used in the neutralization as a function of the pH of the acid reservoir

\begin{tabular}{lcccccc}
\hline $\mathrm{pH}$ & 0 & 1 & 2.2 & 3.4 & 4.3 & 5 \\
\hline $\mathrm{w} /\left(\mathrm{kJ} \mathrm{mol}^{-1}\right)$ & 31.167 & 26.0 & 12.979 & 8.219 & 3.977 & 7.495 \\
$\varepsilon_{\text {neut }}$ & 55.84 & 46.58 & 23.25 & 14.73 & & 2.12 \\
$\frac{\mathrm{W}}{\mathrm{C}_{\mathrm{b}}} /\left(\mathrm{kJ} \mathrm{dm}^{3} \mathrm{~mol}^{-2}\right)$ & 1.95 & 8.67 & $5.57 \times 10^{2}$ & $8.30 \times 10^{3}$ & $3.90 \times 10^{4}$ & $6.01 \times 10^{4}$ \\
\hline
\end{tabular}


processes like the global hydrological cycle ensures the viability of these technologies by maintaining the salinity concentration difference of natural water reservoirs, e.g., river water and seawater. Also, concentration gradients resulting from human actions could be used for energy conversion purposes.

We have also briefly discussed the historical development of some prominent technologies, namely PRO, RED, CapMix, MEB, and NB, with a focus on their working principle. We have provided some insights into the thermodynamic formalism. Additionally, we have detailed the properties that are necessary to assemble MEB and NB cells. We have discussed some literature examples of host matrices that have been investigated as positive and negative electrodes for these systems.

Nowadays, the PRO and RED systems are the most explored. However, these systems rely on membranes, which prevent their practical application. Hence, future developments regarding membrane permeability, selectivity, longevity, and cost are necessary to overcome these limitations. The CapMix and the MEB systems were proposed in the last decade, but the literature on these systems show they are still in the early stages. CapMix systems composed of cheap materials have

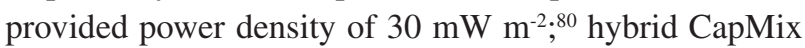
systems have recently afforded $97 \mathrm{~mW} \mathrm{~m}^{-2}$, which points a new direction in this technology. ${ }^{81}$ Nevertheless, future investigations concerning self-discharge processes in the double layer of this system appear to be necessary to improve its efficiency. Energy expenditure during the pre-concentration process, energy loss due to diminished concentration gradient after successive charge/discharge processes, and reversibility of the anion selective electrode are parameters that require further developments in order to make the MEB system viable. Power densities in the order of $60 \mathrm{~mW} \mathrm{~m}^{-2}$ have been obtained for this system. ${ }^{36}$ The NB electrochemical system might provide a valuable asset for renewable energy technologies; additionally, salt concentration gradients could also be used in order to enhance the energy harvesting. ${ }^{82,83} \mathrm{NB}$ could be applied during acidic wastewater treatment, thereby encouraging industrial wastewater treatment and contributing to the sustainable growth of companies that use practices that preserve the environment.

\section{Acknowledgments}

We are grateful to FAPESP (project 2015/16867-9) for financial support.

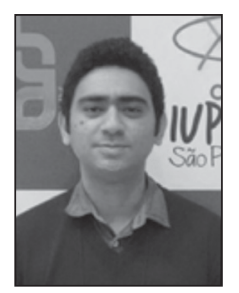

William G. Morais received his Bachelor's degree in Chemistry from Universidade Federal do Rio Grande do Norte (UFRN) in 2010 and his Master's degree from UFRN in 2013. He is currently developing his PhD thesis in Physical Chemistry at Universidade de São Paulo (USP) under guidance of Prof Fritz Huguenin. His research interests are electrochemical systems for energy conversion and storage, and desalination.

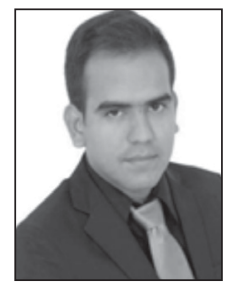

Gilberto Lima graduated in Chemistry at the Universidade Federal do Rio Grande do Norte (UFRN, 2013) and completed his MSc at UFRN (2016). Currently he is a PhD student at Universidade de São Paulo (USP) in the Physical Chemistry area under the supervision of Prof Fritz. Huguenin. His research focus is on electrochemical systems for harvesting energy in a profitable and sustainable way.

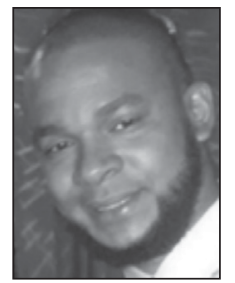

Wellington J. A. S. Gomes graduated in Chemistry (2009) at Faculdade de Filosofia, Ciência e Letras de Ribeirão Preto of Universidade de São Paulo (FFLCRP/USP). He received a Master's degree in Science (2012) and his PhD in Science in 2017 from the same University, working under supervision of Prof Fritz. Huguenin. He is currently Professor of Chemistry at the Instituto Federal de Educação, Ciência e Tecnologia de São Paulo (IFSP), and has experience in electrochemistry, intercalation electrodes, and electroactive materials applied to the field of electrochemical conversion and storage of energy.

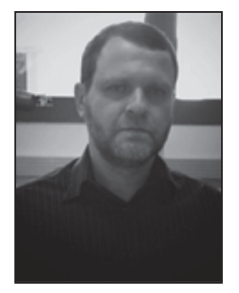

Fritz. Huguenin is Associate Professor at Faculdade de Filosofia, Ciências e Letras (FFCLRP) of Universidade de São Paulo (USP). He received his Bachelor's degree in Chemistry from Universidade Federal do Rio Grande do Norte (UFRN) in 1996. He developed his PhD thesis in 2003 at Instituto de Química de São Carlos (IQSC/USP). He completed two post-doctoral internships at Instituto de Física de São Carlos (IFSC/USP) in 2004 and at Catalan Institute of Nanoscience and Nanotechnology (ICN2) in 2016. His research involves energy conversion, harvesting, and storage. 


\section{References}

1. Ghoniem, A. F.; Prog. Energy Combust. Sci. 2011, 37, 15.

2. Feldman, D. R.; Collins, W. D.; Gero, P. J.; Torn, M. S.; Mlawer, E. J.; Shippert, T. R.; Nature 2015, 519, 339.

3. Yang, Z.; Zhang, J.; Kintner-Meyer, M. C. W.; Lu, X.; Choi, D.; Lemmon, J. P.; Liu, J.; Chem. Rev. 2011, 111, 3577.

4. REN21; Renewables 2016: Global Status Report; REN21 Secretariat: Paris, 2016.

5. Devabhaktuni, V.; Alam, M.; Depuru, S. S. S. R.; Green, R. C.; Nims, D.; Near, C.; Renewable Sustainable Energy Rev. 2013, 19, 555.

6. Khare, V.; Nema, S.; Baredar, P.; Renewable Sustainable Energy Rev. 2016, 58, 23.

7. Panwar, N. L.; Kaushik, S. C.; Kothari, S.; Renewable Sustainable Energy Rev. 2011, 15, 1513.

8. Chang, Z.; Yang, Y.; Li, M.; Wang, X.; Wu, Y.; J. Mater. Chem. A 2014, 2, 10739.

9. Kuleszo, J.; Kroeze, C.; Post, J.; Fekete, B. M.; J. Integr. Environ. Sci. 2010, 7, 89.

10. Jia, Z.; Wang, B.; Song, S.; Fan, Y.; Renewable Sustainable Energy Rev. 2014, 31, 91.

11. Alvarez-Silva, O. A.; Osorio, A. F.; Winter, C.; Renewable Sustainable Energy Rev. 2016, 60, 1387.

12. Logan, B. E.; Elimelech, M.; Nature 2012, 488, 313.

13. Bazhin, N. M.; Desalination 2015, 365, 343.

14. Pasta, M.; Wessells, C. D.; Cui, Y.; La Mantia, F.; Nano Lett. 2012, 12, 839 .

15. Han, G.; Zhang, S.; Li, X.; Chung, T.-S.; Prog. Polym. Sci. 2015, 51,1 .

16. Yip, N. Y.; Vermaas, D. A.; Nijmeijer, K.; Elimelech, M.; Environ. Sci. Technol. 2014, 48, 4925.

17. La Mantia, F.; Pasta, M.; Deshazer, H. D.; Logan, B. E.; Cui, Y.; Nano Lett. 2011, 11, 1810.

18. Yip, N. Y.; Brogioli, D.; Hamelers, H. V.; Nijmeijer, K.; Environ. Sci. Technol. 2016, 50, 12072.

19. Pattle, R. E.; Nature 1954, 174, 660.

20. Kim, J.; Jeong, K.; Park, M.; Shon, H.; Kim, J.; Energies 2015 , $8,11821$.

21. Hong, J. G.; Zhang, B.; Glabman, S.; Uzal, N.; Dou, X.; Zhang, H.; Wei, X.; Chen, Y.; J. Membr. Sci. 2015, 486, 71.

22. Rica, R.; Ziano, R.; Salerno, D.; Mantegazza, F.; van Roij, R.; Brogioli, D.; Entropy 2013, 15, 1388.

23. Facci, T.; Gomes, W. J. A. S.; Bravin, B.; Araujo, D. M.; Huguenin, F.; Langmuir 2014, 30, 426.

24. Levenspiel, O.; de Nevers, N.; Science 1974, 183, 157.

25. Loeb, S.; Norman, R. S.; Science 1975, 189, 654.

26. Brogioli, D.; Phys. Rev. Lett. 2009, 103, 58501.

27. Brogioli, D.; Zhao, R.; Biesheuvel, P. M.; Energy Environ. Sci. 2011, 4, 772 .
28. Bard, A.; Faulkner, L.; Electrochemical Methods: Fundamentals and Applications, $2^{\text {nd }}$ ed.; John Wiley \& Sons: New York, 2001.

29. Conway, B. E.; Birss, V.; Wojtowicz, J.; J. Power Sources 1997, $66,1$.

30. Rica, R. A.; Ziano, R.; Salerno, D.; Mantegazza, F.; Brogioli, D.; Phys. Rev. Lett. 2012, 109, 156103.

31. Hatzell, M. C.; Raju, M.; Watson, V. J.; Stack, A. G.; van Duin, A. C. T.; Logan, B. E.; Environ. Sci. Technol. 2014, 48, 14041.

32. Boon, N.; van Roij, R.; Mol. Phys. 2011, 109, 1229.

33. Sales, B. B.; Saakes, M.; Post, J. W.; Buisman, C. J. N.; Biesheuvel, P. M.; Hamelers, H. V. M.; Environ. Sci. Technol. 2010, 44, 5661.

34. Guo, W.; Cao, L.; Xia, J.; Nie, F.-Q.; Ma, W.; Xue, J.; Song, Y.; Zhu, D.; Wang, Y.; Jiang, L.; Adv. Funct. Mater. 2010, 20, 1339.

35. Marino, M.; Misuri, L.; Carati, A.; Brogioli, D.; Energies 2014, 7, 3664.

36. Ye, M.; Pasta, M.; Xie, X.; Cui, Y.; Criddle, C. S.; Energy Environ. Sci. 2014, 7, 2295.

37. Jia, Z.; Wang, B.; Song, S.; Fan, Y.; RSC Adv. 2013, 3, 26205.

38. Tehrani, S. H. M. H.; Seyedsadjadi, S. A.; Ghaffarinejad, A.; RSC Adv. 2015, 5, 30032.

39. Bravin, B.; Gomes, W. J. A. S.; Huguenin, F.; J. Electroanal. Chem. 2016, 765, 52.

40. Morais, W. G.; Gomes, W. J. A. S.; Huguenin, F.; J. Phys. Chem. C 2016, 120, 17872.

41. Karyakin, A. A.; Electroanalysis 2001, 13, 813.

42. Maspoch, D.; Ruiz-Molina, D.; Veciana, J.; Chem. Soc. Rev. 2007, 36, 770.

43. García-Jareño, J. J.; Navarro, J. J.; Roig, A. F.; Scholl, H.; Vicente, F.; Electrochim. Acta 1995, 40, 1113.

44. Neff, V. D.; J. Electrochem. Soc. 1985, 132, 1382.

45. Itaya, K.; Ataka, T.; Toshima, S.; J. Am. Chem. Soc. 1982, 104, 4767.

46. Ho, K.-C.; Lin, C.-L.; Sens. Actuators, B 2001, 76, 512.

47. Wessells, C. D.; McDowell, M. T.; Peddada, S. V.; Pasta, M.; Huggins, R. A.; Cui, Y.; ACS Nano 2012, 6, 1688.

48. Yue, Y.; Binder, A. J.; Guo, B.; Zhang, Z.; Qiao, Z.-A.; Tian, C.; Dai, S.; Angew. Chem., Int. Ed. 2014, 53, 3134.

49. Wu, X.; Cao, Y.; Ai, X.; Qian, J.; Yang, H.; Electrochem. Commun. 2013, 31, 145.

50. Wu, X.-Y.; Sun, M.-Y.; Shen, Y.-F.; Qian, J.-F.; Cao, Y.-L.; Ai, X.-P.; Yang, H.-X.; ChemSusChem 2014, 7, 407.

51. Nie, P.; Shen, L.; Luo, H.; Ding, B.; Xu, G.; Wang, J.; Zhang, X.; J. Mater. Chem. A 2014, 2, 5852.

52. Jia, Z.; Wang, J.; Wang, Y.; RSC Adv. 2014, 4, 22768.

53. Pasta, M.; Wessells, C. D.; Huggins, R. A.; Cui, Y.; Nat. Commun. 2012, 3, 1149.

54. Wessells, C. D.; Peddada, S. V.; Huggins, R. A.; Cui, Y.; Nano Lett. 2011, 11, 5421.

55. Lu, Y.; Wang, L.; Cheng, J.; Goodenough, J. B.; Chem. Commun. 2012, 48, 6544 . 
56. Lee, H.; Kim, Y.-I.; Park, J.-K.; Choi, J. W.; Chem. Commun. 2012, 48, 8416.

57. Liu, N.; Li, W.; Pasta, M.; Cui, Y.; Front. Phys. 2014, 9, 323.

58. Wessells, C. D.; Peddada, S. V.; McDowell, M. T.; Huggins, R. A.; Cui, Y.; J. Electrochem. Soc. 2012, 159, A98.

59. Malik, M. A.; Miecznikowski, K.; Kulesza, P. J.; Electrochim. Acta 2000, 45, 3777.

60. Siperko, L. M.; Kuwana, T.; J. Electrochem. Soc. 1983, 130, 396.

61. Gomes, W. J. A. S.; de Oliveira, C.; Huguenin, F.; Langmuir 2015, 31, 8710.

62. Novák, P.; Müller, K.; Santhanam, K. S. V.; Haas, O.; Chem. Rev. 1997, 97, 207.

63. Gangopadhyay, R.; De, A.; Chem. Mater. 2000, 12, 608.

64. Mahmud, H. N. M. E.; Huq, A. K. O.; Yahya, R. B.; RSC Adv. 2016, 6, 14778.

65. Afzal, A.; Abuilaiwi, F. A.; Habib, A.; Awais, M.; Waje, S. B.; Atieh, M. A.; J. Power Sources 2017, 352, 174.

66. Song, Y.; Liu, T.-Y.; Xu, X.-X.; Feng, D.-Y.; Li, Y.; Liu, X.-X.; Adv. Funct. Mater. 2015, 25, 4626.

67. Wang, G. J.; Yang, L. C.; Qu, Q. T.; Wang, B.; Wu, Y. P.; Holze, R.; J. Solid State Electrochem. 2009, 14, 865.

68. Yuan, Y. J.; Adeloju, S. B.; Wallace, G. G.; Eur. Polym. J. 1999, $35,1761$.

69. Ji, Y.; Huang, L.; Hu, J.; Streb, C.; Song, Y.-F.; Energy Environ. Sci. 2015, 8, 776.

70. Quintana, M.; López, A. M.; Rapino, S.; Toma, F. M.; Iurlo, M.; Carraro, M.; Sartorel, A.; Maccato, C.; Ke, X.; Bittencourt, C.; Da Ros, T.; Van Tendeloo, G.; Marcaccio, M.; Paolucci, F.; Prato, M.; Bonchio, M.; ACS Nano 2013, 7, 811.
71. Dolbecq, A.; Dulmas, E.; Meyer, C. R.; Mialane, P.; Chem. Rev. 2010, 110, 6009.

72. Omwoma, S.; Chen, W.; Tsunashima, R.; Song, Y.-F.; Coord. Chem. Rev. 2014, 258, 58.

73. Sadakane, M.; Steckhan, E.; Chem. Rev. 1998, 98, 219.

74. Suppes, G. M.; Cameron, C. G.; Freund, M. S.; J. Electrochem. Soc. 2010, 157, A1030.

75. Et Taouil, A.; Lallemand, F.; Hihn, J. Y.; Melot, J. M.; BlondeauPatissier, V.; Lakard, B.; Ultrason. Sonochem. 2011, 18, 140.

76. Branzoi, F.; Branzoi, V.; Open J. Org. Polym. Mater. 2015, 5 , 89.

77. Du, X.; Wang, Z.; Electrochim. Acta 2003, 48, 1713.

78. Mo, D.; Zhou, W.; Ma, X.; Xu, J.; Zhu, D.; Lu, B.; Electrochim. Acta 2014, 132, 67.

79. Toth, P. S.; Janaky, C.; Berkesi, O.; Tamm, T.; Visy, C.; J. Phys. Chem. B 2012, 116, 5491.

80. Marino, M.; Misuri, L.; Jimenez, M. L.; Ahualli, S.; Kozynchenko, O.; Tennison, S.; Bryjak, M.; Brogioli, D.; J. Colloid Interface Sci. 2014, 436, 146.

81. Lee, J.; Yoon, H.; Lee, J.; Kim, T.; Yoon, J.; ChemSusChem 2017, 10, 1600.

82. Lima, G.; Morais, W. G.; Gomes, W. J. A. S.; Huguenin, F.; Phys. Chem. Chem. Phys. 2017, 19, 31202.

83. Morais, W. G.; Lima, G.; Huguenin, F. In Nanoenergy: Nanotechnology Applied for Energy Production, $2^{\text {nd }}$ ed.; de Souza, F. L.; Leite, E., eds.; Springer International Publishing: Cham, 2018

Submitted: October 12, 2017 Published online: January 22, 2018 